\title{
Efficacy of Chlorine Sanitizer Spray Bottles Exposed to Various Temperatures and Ambient Light
}

\author{
by \\ Jan Kobylarz \\ PROJECT SUBMITTED IN PARTIAL FULFILLMENT OF \\ THE REQUIRMENT FOR THE DEGREE OF \\ Bachelor of Technology in Environmental Health \\ C Jan Kobylarz \\ BRITISH COLUMBIA INSTITUTE OF TECHNOLOGY \\ April 2017
}

All rights reserved. This work may not be reproduced in whole or in part, by photocopy or other means, without permission of the author 


\title{
Efficacy of Chlorine Sanitizer Spray Bottles Exposed to Various Temperatures and Ambient Light
}

Jan Kobylarz', Helen Heacock², Fred Shaw ${ }^{3}$

1 Lead Author, B. Tech Student of Health Sciences, British Columbia Institute of Technology, 3700 Willingdon Ave, Burnaby, BC V5G $3 \mathrm{H} 2$

2 Supervisor, School of Health Sciences, British Columbia Institute of Technology, 3700 Willingdon Ave, Burnaby, BC V5G 3H2 3 Contributor, School of Health Sciences, British Columbia Institute of Technology, 3700 Willingdon Ave, Burnaby, BC V5G 3H2

\begin{abstract}
Background: Gastroenteritis is largely under reported across Canada. It is estimated that one reported case represents on average 313 cases. In addition, improper cleaning is one of the top ten reported causes of food borne illness. Sanitization is important to reduce the number of pathogenic microorganisms present on food contact surfaces to a safe level. Correct concentrations of sodium hypochlorite are to be prepared and used within the range of $100 \mathrm{ppm}-$ $200 \mathrm{ppm}$ on food contact surfaces. The purpose of this study was to evaluate the rate of degradation of sodium hypochlorite in spray bottles to assess if these solutions need to be prepared fresh daily to achieve efficacy. Two variables seen within a food service establishment were chosen to evaluate the rate of degradation, temperature and ambient light.

Method: Room temperature $\left(20^{\circ} \mathrm{C}\right), 35^{\circ} \mathrm{C}$ and ambient light exposure were tested to evaluate their effect on the degradation of free chlorine in spray bottles over time in days. The experiment was preformed by setting up 3 individual spray bottles at $20^{\circ} \mathrm{C}$ with no light, $20^{\circ} \mathrm{C}$ with ambient light and $35^{\circ} \mathrm{C}$ with no light. The sodium hypochlorite was then sampled and recorded periodically three times a week over a 15-day period to determine the stability of the chorine solutions prepared at around 200ppm.

Results: In the order of spray bottles tested, $20^{\circ} \mathrm{C}$ no light, $20^{\circ} \mathrm{C}$ ambient light and $35^{\circ} \mathrm{C}$ no light, a correlation coefficient of $-0.3027,-0.8235$ and -0.8169 were recorded. In addition, the following test spray bottles held a r-squared value of 0.0916, 0.6781 and 0.6674 . A p-value of $0.5094,0.0249$ and 0.0249 were also assessed, with a corresponding power of $8.99 \%, 73.74 \%$ and $71.75 \%$.

Conclusions: By calculating the linear regression formula, it was concluded that chlorine solution in spray bottles do not need to be prepared fresh daily. For $200 \mathrm{ppm} 20^{\circ} \mathrm{C}$ no light, $200 \mathrm{ppm} 20^{\circ} \mathrm{C}$ ambient light and $200 \mathrm{ppm} 35^{\circ} \mathrm{C}$ no light, at days 128,67 and 45 , the estimated concentration of sodium hypochlorite will be at the minimum requirement of $100 \mathrm{ppm}$ respectively.
\end{abstract}

Keywords: chlorine, sodium hypochlorite, sanitizer, spray bottle, temperature, ambient light 


\section{Introduction}

Globalization of food supplies has resulted in an increased incidence of gastroenteritis occurring within food service establishments. Across Canada, confirmed cases of gastroenteritis are largely underreported. Public health studies have estimated that one acute case of gastroenteritis reported to a Provincial Health Authority represents on average 313 cases (1). To limit the spread of pathogen transmission, Health Canada along with the Bureau of Chemical Safety and Food Directorate have established regulations for acceptable food contact surface sanitizers. (2)

Sanitization is important for food service establishments. Sanitization allows for the reduction or limit in the number of pathogenic microorganisms to a safe level. Improper cleaning of food contact surfaces is one of the top 10 causes of foodborne illness. To ensure the efficacy of sanitization on food contact surfaces, sanitization procedures require a 5 -log reduction of all microorganisms within a 30 second contact period. $(2,3)$ The most popular sanitizers among food service establishments is chlorine due to their convenience, low cost, effectiveness and residual bactericidal effect. (4) In BC both guidelines and regulations pertaining to food contact surfaces generalize that these surfaces are sanitized in a manner that ensures safety. $(5,6)$ Preparation of this approved sanitizer involves mixing as per product instructions. To achieve the 5-log reduction, it is recommended that these solutions are made up fresh daily. Over time, these sanitizer solutions can degrade by external and internal environmental factors such as $\mathrm{pH}$, temperature, concentration, soiled material, and light. (3)
To increase the stability of prepared sanitizer solutions, it is recommended to most food service establishments that sanitizer solutions are prepared in sealed containers such as a spray bottle. The main concern regarding a sealed container practice is that over time, operators may neglect to re-make their sanitizer solutions. These prepared sanitizer solutions are typically stored within the kitchen of food service establishments thus resulting in an increased exposure to harsh external environmental factors such as higher temperatures and constant ambient light exposure. As mentioned earlier these two factors can play a large part on the efficacy of sanitizer solutions. Having greater education on the amount of time diluted sanitizer solutions can be kept in prepared bottles should increase the overall efficacy of food contact surface sanitation and decrease the incidence of gastroenteritis.

\section{Evidence Review}

\section{Sanitizers Vs Disinfectants}

Sanitization and disinfection of contact surfaces is a widespread practice required within all levels of the food industry. Quite frequently, the terms to sanitize and to disinfect are improperly used. Although they are both very similar in definition, within the food industry the end results of each used in practice are very different. Disinfection is the elimination of all viable infectious microorganisms by irreversible inactivation. In contrast sanitization is only the reduction of infectious microorganisms to acceptable levels. Within each level of the food industry, both disinfection and sanitization procedures are implemented but only sanitization procedures are found to be the most beneficial and thus are the most commonly used. The benefits associated 
with sanitizer solutions are their ability to simultaneously clean and disinfect to safe levels that will not affect a food products' quality. (3)

There are many approved sanitizer solutions circulating in the food industry and each sanitizer has its own procedure. Most sanitizer solutions vary in how they are prepared and applied to contact surfaces to achieve efficacy. To name a few: Chlorine compounds, peroxide compounds, acid anionic, carboxylic acid, hydrogen peroxide and quaternary ammonium compounds are all sanitizers approved by Health Canada. (2) For the purposes of this review, focus has only been given to chlorine compounds because they are most commonly used by food industry operators. (4) Overall, the sanitizers used on food contact surfaces can be very effective when prepared and monitored at their respective concentrations, but there are also limitations. The efficacy of a sanitizer solutions to produce a 5-log reduction is greatly affected by many different variables within an environment. Murine norovirus, for example, is an infectious microorganism that is known to be greatly more resistant under identical sanitization procedures when compared to other microorganisms. Under standard warewashing operations both chlorine and quaternary ammonium sanitizers only reduced murine norovirus by a maximum of 3-log contrary to the required 5-log reduction. (7)

In summation, the factors that decrease the efficacy of sanitizers are important to monitor. The most common and controllable factors within a food service establishment are both temperature and ambient light. Thus, focus has been placed on temperature and ambient light as environmental factors affecting the efficacy of chlorine when stored within a food service establishment.

\section{Chlorine Compounds}

Preparation of chlorine based sanitizer solutions are very common among food service establishments. Chlorine based sanitizers are generally a low costing alternative and a strong oxidizer, thus are used frequently by many food service operators. (3) Chlorine can be a very effective sanitizer at the correct concentrations. Chlorine solutions are generally prepared between $150 \mathrm{ppm}-$ 200ppm. (2) It is widely recommended to dilute household bleach from a concentration of $5.25 \%$ to that of $0.05 \%$ for hand washing and $0.5 \%$ for food contact surfaces. At these lower chlorine concentrations, the sodium hypochlorite is more susceptible to internal and external environmental factors. (8) One of the factors that effects chlorine's efficacy is $\mathrm{pH}$. (9) Depending on the $\mathrm{pH}$ of a chlorine sanitizer solution, it can either increase the storage or increase the efficacy of antimicrobial activity but not both. Low $\mathrm{pH}$ levels are more reactive against microorganisms but less stable during extended storage. In comparison, the near neutral $\mathrm{pH}$ chlorine sanitizer solutions were less affective but greatly more stable during storage. (9)

Environmental factors such as temperature and light can also have a measurable effect on the shelf-life of chlorine during storage and even more so on chlorine solutions that are diluted. (10) When considering the effects of $\mathrm{pH}$ on chlorine sanitizers in food services establishments, it is considerably less reasonable for a food service operator to control than the external environmental factors such as temperature and ambient light. (11) Thus, focus will remain on assessing the effects temperature and ambient light have on sodium hypochlorite. 


\section{Light \& Temperature Effects on Sodium Hypochlorite}

Within food service establishments, chlorine sanitizers intended to clean contact food surfaces are prepared either in open faced pails with a wash cloth or within polyethylene bottles. Rulala, Cole, Thomann and Weber (1998) tested the stability of chlorine solutions in various containers diluted to 1:5, 1:50 and 1:100 from 5.25\% bleach over 30 days at $20^{\circ} \mathrm{C}$. (14) The various containers tested consisted of translucent spray bottles and capped bottles that were both either left open or closed. The control was a brown opaque bottle that showed very little degradation over the 30 days. In conclusion, they had found that these solutions within the translucent bottles were still stable $(>100 \mathrm{ppm})$ after 30 days and that the preparation of fresh solutions daily was an unnecessary practice. Aside from the overall stability, is was surprising to see that the effects an open environment had on the open bottles compared to the closed bottles at lower dilutions. At lower dilutions, both the open and closed bottles had similar trends in ppm degradation over the 30 days. As confirmed by Law (2002) chlorine is more resistant to degradation at higher concentrations. (15) A parameter that was not addressed involved the storage of chlorine at different temperatures. The average temperature within the kitchen of a busy food service establishment can range from $25^{\circ} \mathrm{C}$ to $35^{\circ} \mathrm{C}$, thus further studies on the storage of chlorine spray bottles within an environment that reflects an average kitchen environment is important.

\section{Literature on Sodium Hypochlorite}

Within the academic field, there are numerous articles on the effects that both temperature and light may have on sodium hypochlorite. Most of the literature around this topic is related more specifically to studies that ascertained the efficacy of these two sanitizers against pathogenic microorganisms. (4) Although there were plenty of laboratory studies, fewer studies were represented within the field. In addition, there were even fewer studies specifically addressing the effects temperature and light have on the stability of sanitizer solutions when prepared at a 100200ppm range within sealed bottles. (14) When Health Authorities educate operators, they rely on the product label to recommend a rule of best practice when preparing sanitizer solutions, but in truth these product labels may underestimate the products actual stability. Of the few studies that did look at the degradation of prepared sanitizer solutions around the range of 100-200ppm, limited temperature ranges were analysed. (8) After completing a concise literature review, no scientific study was designed to be representative of a food service establishment environment.

\section{Conclusion}

Upon review, it was found sodium hypochlorite prepared in bottled containers were vastly more stable than exposed containers. Evidence also strongly supported that sodium hypochlorite solutions prepared in opaque bottles are stable over consecutive days. Of the two external environmental factors, temperature produces the greatest effect on sanitizer stability while ambient light typically showed a small affect when sanitizer solutions were stored within transparent containers. The purpose of this study was to further research the effects temperature and ambient light have on chlorine sanitizers. Furthermore, it is important to ascertain if greater education should be made on the storage practices of 
prepared sanitizer solution spray bottles intended for food contact surfaces.

\section{Methods}

\section{Purpose}

Methods and materials were designed to measure sodium hypochlorite within the range of $0-200 \mathrm{ppm}$. The goal was to assess how prepared chlorine solutions in spray bottles degrade over time below the recommended 100ppm concentration. Varying temperature and light exposures were tested to reflect a food service establishment setting. (14)

\section{Description of Materials}

\begin{tabular}{|c|c|}
\hline Material & Reason \\
\hline $\begin{array}{l}\text { Chlorine } \\
\text { (House } \\
\text { Hold } \\
\text { Bleach, } \\
\text { Clorox) } \\
5.25 \%\end{array}$ & $\begin{array}{l}\text { Most commonly used } \\
\text { sanitizer in food service } \\
\text { establishment. Used to } \\
\text { prepare chlorine solutions } \\
\text { within the range of } 100- \\
200 \mathrm{ppm} \text {. }\end{array}$ \\
\hline Tap water & $\begin{array}{l}\text { Most assessable solvent for } \\
\text { food service establishments. } \\
\text { Used to dilute chlorine } \\
\text { sanitizer solutions to the } 100 \text { - } \\
200 \text { ppm range. }\end{array}$ \\
\hline $\begin{array}{l}\text { Standard } \\
\text { plastic } \\
\text { opaque } \\
\text { spray } \\
\text { bottle } \\
\text { (1L) } \\
\text { Total } 4\end{array}$ & In \\
\hline & $\begin{array}{l}\text { Commonly used spray bottle } \\
\text { in food service } \\
\text { establishments. }\end{array}$ \\
\hline $\begin{array}{l}\text { Incubator } \\
\text { at } 35^{\circ} \mathrm{C}\end{array}$ & $\begin{array}{l}\text { Peak average kitchen } \\
\text { temperature within a food }\end{array}$ \\
\hline
\end{tabular}

\begin{tabular}{|c|c|}
\hline & $\begin{array}{l}\text { service establishment and a } \\
\text { parameter to be tested. }\end{array}$ \\
\hline $\begin{array}{l}\text { Digital } \\
\text { Pipette } \\
(20 \mu \mathrm{L}- \\
200 \mu \mathrm{L})\end{array}$ & $\begin{array}{l}\text { Its purpose was for diluting } \\
\text { the prepared chlorine } \\
\text { solutions during the } \\
\text { experiment within cuvettes to } \\
1 / 100^{\text {th }} \text {. This dilution serves } \\
\text { to allow the ColorQ } \\
\text { photometer to accurately } \\
\text { enumerate the free chorine of } \\
\text { the experiment within the } \\
\text { photometers range of } 0 \mathrm{ppm}- \\
10 \mathrm{ppm} \text {. }\end{array}$ \\
\hline $\begin{array}{l}\text { LaMotte } \\
\text { ColorQ } \\
\text { photomet } \\
\text { er }\end{array}$ & $\begin{array}{l}\text { Used to quantify the amount } \\
\text { of free chlorine accurately. } \\
\text { ColorQ utilizes a dual-optic } \\
\text { design to enumerate and } \\
\text { display a digital reading with } \\
\text { the range of 0ppm- 10ppm } \\
\text { free chlorine. This device } \\
\text { increases the experiment's } \\
\text { accuracy by eliminating the } \\
\text { need to visually determine } \\
\text { slight color variations used by } \\
\text { other methods. }\end{array}$ \\
\hline $\begin{array}{l}\text { Black } \\
\text { Tape }\end{array}$ & $\begin{array}{l}\text { To blackout an experiment } \\
\text { spray bottle such that it will } \\
\text { have no ambient light } \\
\text { exposure. }\end{array}$ \\
\hline $\begin{array}{l}5 \mathrm{~mL} \\
\text { pipette }\end{array}$ & $\begin{array}{l}\text { Used to measure the chlorine } \\
\text { in order to prepare } 100- \\
200 \text { ppm solutions within } 1 \mathrm{~L} \\
\text { spray bottles. } \\
\text { Used for the } 1 / 100^{\text {th }} \text { chlorine } \\
\text { dilutions within the ColorQ } \\
\text { cuvette. }\end{array}$ \\
\hline $\begin{array}{l}\text { Cyanuric } \\
\text { Acid }\end{array}$ & $\begin{array}{l}\text { Prepared } 30-50 \mathrm{ppm} \text { with the } \\
\text { dilution solution. }\end{array}$ \\
\hline
\end{tabular}


Used to stabilize the chlorine dilutions.

\section{Description of Standard Methods}

This experiment included the preparation of chlorine solutions within a total of 3 opaque spray bottles. One of the three opaque bottles intended to incubate at room temperature was taped to blackout ambient light exposure. The acceptable concentration for chlorine as an effective contact surface sanitizer ranges from 100200ppm. (2) Since 200ppm is the maximum concentration that chlorine solutions may be applied without rinsing and because most health authorities recommend that chlorine spray bottle solutions are prepared at $200 \mathrm{pm}$, the recommended dilution of $5 \mathrm{~mL}$ of $5.25 \%$ Clorox (house hold bleach) to $95 \mathrm{~mL}$ of tap water were prepared. $(14,2)$ This concentration was exposed to two independent environmental factors known to degrade free chlorine, temperature and ambient light. The temperatures chosen to be tested, were at room temperature $\left(\sim 20^{\circ} \mathrm{C}\right)$ and $35^{\circ} \mathrm{C}$. Furthermore, only the room temperature bottles were exposed to either the absence or presence of ambient light as depicted within Table 1.

A ColorQ photometer was used to determine the concentration of free chlorine within the prepared spray bottles throughout the experiment. At the start of each sampling day, each prepared solution was inverted then diluted by $1 / 100^{\text {th }}$ and measured by ColorQ. (15) This dilution serves to allow the ColorQ photometer to enumerate the free chorine of the experiment within the photometer's range of 0ppm-10ppm. A dilution factor of 100 was then implemented to calculate the true concentration of free chlorine within each prepared spray bottle. (16)

To prepare the dilution for the ColorQ, $50 \mu \mathrm{L}$ was aliquoted from each of the three test bottles and diluted with $4500 \mu \mathrm{L}$ of a $30-50$ ppm cyanuric acid tap water solution within a ColorQ cuvette to sample. The cyanuric acid dilution solution was stored within a fourth spray bottle filled the same day as the test sample spray bottles were prepared. By storing the make up water in the same bottle for the same number of sample dates, helped to reduce the effect of any confounding variable in tap water quality. Each sample was tested 3 times to calculate a mean average of sodium hypochlorite concentration during each sampling period.

Table 1. Three opaque spray bottles prepared with a chlorine concentration within 100-200ppm and a forth with a cyanuric acid concentration of 30-50ppm.

Two of the three chlorine concentration bottles were exposed to $20^{\circ} \mathrm{C}$ with either no light or ambient light, where as the third bottle was exposed to $35^{\circ} \mathrm{C}$ and no light.

\begin{tabular}{|l|l|l|l|}
\hline $\begin{array}{l}\text { Bottle } \\
\#\end{array}$ & $\begin{array}{l}\text { External } \\
\text { Factors }\end{array}$ & $\begin{array}{l}\text { Sodium } \\
\text { Hypochlorite [ ] }\end{array}$ & $\begin{array}{l}\text { Cyanuric Acid } \\
\text { Concentration }\end{array}$ \\
\hline 1 & Temp: & $100-200 \mathrm{ppm}$ & \\
& $20^{\circ} \mathrm{C}$ & & \\
& No Light & & \\
\hline 2 & Temp: & $100-200 \mathrm{ppm}$ & \\
& $20^{\circ} \mathrm{C}$ \\
& Ambient & & \\
& Light & & \\
\hline 3 & Temp: & $100-200 \mathrm{ppm}$ & \\
& $35^{\circ} \mathrm{C}$ & & \\
& No Light & & $30-50 \mathrm{ppm}$ \\
\hline 4 & Temp: & & \\
& $20^{\circ} \mathrm{C}$ & & \\
& Ambient & & \\
& Light & & \\
\hline
\end{tabular}

\section{Calibration of Instruments}

To calibrate the ColorQ, a blank sample was required to be measured before adding the reagents to enumerate the free chlorine within the sample aliquoted. (17) 


\section{Statistical Analysis}

In determining the degradation of free chlorine, continuous data was collected. Therefore, numerical data was interpreted during the experiment. A simple linear regression was used to identify a correlation between two variables to allow for the interpolation of data using the best-fitting line equation. The independent and dependent variables are time and the concentration of free chlorine respectively. Data was organized by using Excel and a simple linear regression with descriptive data for each spray bottle was drafted using NCSS 11. (18)

\section{Results}

\section{Descriptive Statistics}

$\mathrm{H}_{\mathrm{o}}=$ Free chlorine solutions prepared within a spray bottle is stable.

$\mathrm{H}_{\mathrm{a}}=$ Free chlorine solutions prepared within a spray bottle degrades over time.

Or statistically

$\mathrm{H}_{\mathrm{o}}=$ slope is equal to 0 .

$\mathrm{H}_{\mathrm{a}}=$ slope is not equal to 0 .

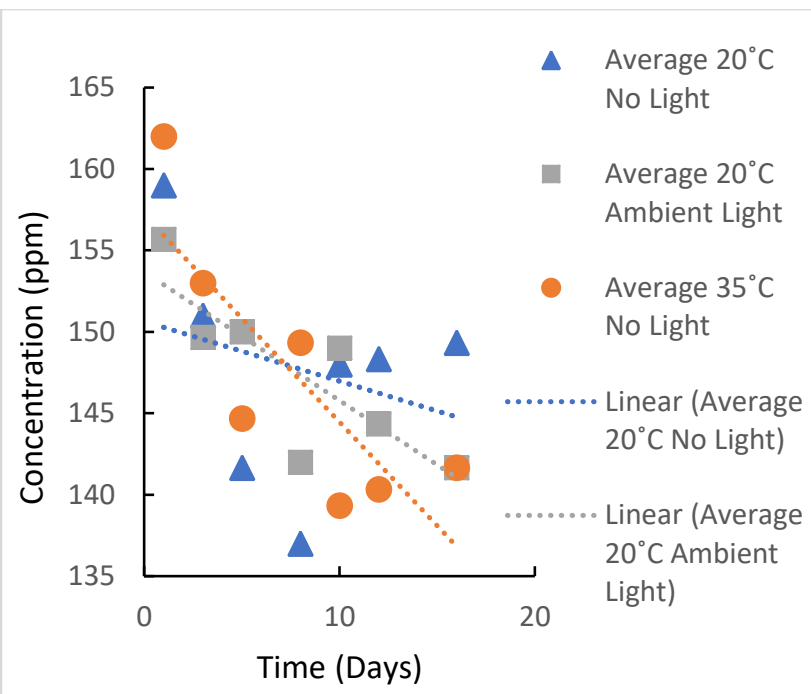

Figure 1. Degredation of 5.25\% Clorox bleach prepared in spray bottles exposed to temperature and light variables.

Table 3. Statistical data from NCSS of $5.25 \%$ Clorox bleach prepared in spray bottles exposed to temperature and light variables

\begin{tabular}{|l|l|l|l|}
\hline & $\begin{array}{l}\text { Spray } \\
\text { Bottle } \\
\text { at } 20^{\circ} \mathrm{C} \\
\text { No } \\
\text { Light }\end{array}$ & $\begin{array}{l}\text { Spray } \\
\text { Bottle } \\
\text { at } 20^{\circ} \mathrm{C} \\
\text { Ambien } \\
\text { t Light }\end{array}$ & $\begin{array}{l}\text { Spray } \\
\text { Bottle } \\
\text { at } 35^{\circ} \mathrm{C} \\
\text { No } \\
\text { Light }\end{array}$ \\
\hline $\begin{array}{l}\text { Correlation } \\
\text { Coefficient }\end{array}$ & -0.3027 & -0.8235 & -0.8169 \\
\hline $\mathrm{r}^{2}$ & 0.0916 & 0.6781 & 0.6674 \\
\hline p-value & 0.5094 & 0.0228 & 0.0249 \\
\hline Slope Power & $8.99 \%$ & $73.74 \%$ & $71.75 \%$ \\
\hline Slope & $\begin{array}{l}{[]=} \\
(150.83\end{array}$ & $\begin{array}{l}{[]=} \\
(153.90\end{array}$ & $\begin{array}{l}{[]=} \\
(157.16 \\
15)+(- \\
61)+(- \\
1.2757)\end{array}$ \\
\hline $\begin{array}{l}56)+(-8057) \\
(\text { Day })\end{array}$ \\
\hline $\begin{array}{l}\text { Day at } \\
\text { 100ppm } \\
\text { Sodium } \\
\text { Hypochlorite }\end{array}$ & 128 & 67 & 45 \\
\hline
\end{tabular}

\section{Inferential Statistics}

Spray Bottles at $20^{\circ} \mathrm{C}$ with No Light 
After running the data through NCSS 11 , the correlation coefficient is equal to 0.3027 showing that there is a negative correlation between free chlorine and time. This means that the free chlorine is degrading over time. A r-squared value of 0.0916 suggests that the data collected poorly fits the line of regression.

The linear regression equation is estimated as Average_20_C_No_Light $(\mathrm{ppm})=(150.8356)+(-0.39 \overline{7} 3)$ (Day). At day 128 , the estimated concentration of sodium hypochlorite will be at the minimum requirement of $100 \mathrm{ppm}$.

From the linear regression report a $\mathrm{p}$ value of 0.5094 is calculated. This value indicates that we can not reject the null hypothesis of the slope being equal to 0 . A power $8.99 \%$ strongly suggests that there may not enough sufficient data points collected to confidently reject the null hypotheses.

\section{Spray Bottles at $20^{\circ} \mathrm{C}$ with Ambient Light}

A strong negative correlation

represented by the degradation of free chlorine over time as -0.8235 is seen for the spray bottle at $20^{\circ} \mathrm{C}$ with ambient light. A rsquared value of 0.6781 supports that the data collected moderately fits the line of regression.

The linear regression equation is estimated as Average_20_C_Ambient_Light $(\mathrm{ppm})=(153.9015)+(-0.8057)($ Day $)$. From the linear regression equation calculated, the minimum regulatory concentration of $100 \mathrm{ppm}$ would be reached on day 67.

From the linear regression report, a p-value of 0.0228 is calculated. Therefore, reject the null hypothesis and accept the alterative hypothesis that the concentration of sodium hypochlorite decreases over time. A power of $73.74 \%$ moderately supports that there are sufficient data points collected to reject the null hypotheses of the slope being equal to 0 .

\section{Spray Bottles at $35^{\circ} \mathrm{C}$ with No Light}

Similar to the statistical data of other two, the correlation coefficient of -0.8169 shows that free chlorine is degrading over time. A r-squared value of 0.6674 supports that the data collected also moderately fits the line of regression.

The linear regression equation is estimated as Average_35_C_No_Light $(\mathrm{ppm})=(157.1661)+(-1.2757)($ Day $)$. The degradation of chlorine per day is (-1.2757). As calculated from the linear regression equation, the $y$-axis intercept is equal to (212.1793) when $\mathrm{x}$ is equal to 0 . At day 45, the concentration of residual sodium hypochlorite would be at the minimum requirement of $100 \mathrm{pm}$.

From the linear regression report, a p-value of 0.0249 is calculated. This value for the spray bottle at $35^{\circ} \mathrm{C}$ and no light indicated that we can reject the null hypothesis. A power of 0.7175 or $71.75 \%$ moderately supports that there are sufficient data points collected to reject the null hypotheses.

\section{Discussion}

From this study, available sodium hypochlorite solutions prepared within opaque spray bottles were found to be stable for up to two weeks. Stability was evaluated under the condition that the test solution prepared could maintain an available sodium hypochlorite concentration between 100$200 \mathrm{ppm}$. As opposed to the recommendation from health agencies, each spray bottle needs to be prepared fresh daily, each opaque spray bottle tested maintained a concentration greater than $100 \mathrm{ppm}$ available sodium hypochlorite over a 15-day period (2).

Each opaque spray bottle sampled showed a consistent degradation of available sodium hypochlorite. As confirmed by the study Clarkson et al performed on the loss of 
available sodium hypochlorite in solutions exposed to light and temperature, the largest degradation of free chlorine occurred within the opaque spray bottle exposed to an increase in temperature (11). Temperature, as opposed to ambient light had the largest effect on available sodium hypochlorite because opaque spray bottles prevent most of the effects ambient light would have on degrading available sodium hypochlorite. When comparing the two opaque spray bottles stored at $20^{\circ} \mathrm{C}$, the bottle exposed to ambient light had a slightly larger decrease in available free chlorine than the bottle not exposed to ambient light. This trend is also shown by a study preformed by Rutala et al, where higher concentrations of sodium hypochlorite were prepared within both a closed brown bottle and an opaque bottle (12). The available sodium hypochlorite concentration within the brown bottle remained stable compared to the opaque bottle over 30-days. During this experiment conducted, degradation is still seen in the blacked-out opaque spray bottle because the solutions tested were 10 times more dilute than the solutions prepared by Rutala et al and sodium hypochlorite is less stable at lower dilutions (12). In addition, there was not a large amount of indirect sunlight exposure on the prepared sodium hypochlorite solutions. This resulted in both solutions stored at $20^{\circ} \mathrm{C}$ to degrade at similar rates. The effects ultraviolet light had on available sodium hypochlorite was diminished by being indoors and within opaque spray bottles as is typical for sodium hypochlorite solutions stored within a food service establishment.

From the linear regression, it is suggested that at days 128, 67 and 45 the concentration of available sodium hypochlorite will be below the required 100$200 \mathrm{ppm}$ range for the opaque spray bottle stored at $20^{\circ} \mathrm{C}$ no light, $20^{\circ} \mathrm{C}$ ambient light and $35^{\circ} \mathrm{C}$ no light respectively. The linear regression calculated from both the opaque spray bottle stored at $20^{\circ} \mathrm{C}$ ambient light and $35^{\circ} \mathrm{C}$ no light held a moderately strong linear regression with $\mathrm{r}$-squared values of 0.6781 and 0.6674 respectively. This moderately strong linear regression supports that these two bottles will be stable for longer than a month. Where as there is a weak linear regression for the opaque spray bottle stored at $20^{\circ} \mathrm{C}$ no light with a r-squared value of 0.0916 attributed largely by human error. The expected date to which this opaque spray bottle falls below the 100-200ppm range may not be concluded due to the samples poor correlation with its trend. Regardless it is safe to assume all three solutions are stable after the 15-day sampling period.

\section{Limitations}

During the study, restraint was put on the method used to enumerate the available sodium hypochlorite. Time, money and a restricted access to equipment all played a large part in choosing ColorQ as opposed to a more accurate large-scale titration to calculate the available sodium hypochlorite within the 100-200 ppm range. Thus, some precision was lost during sampling and when constructing the linear regressions.

By using ColorQ, only available sodium hypochlorite concentrations within a $0-10 \mathrm{ppm}$ range could be measured (16). This meant that a dilution of $1: 100^{\text {th }}$ had to be performed on the solutions prepared within each opaque spray bottle before being read with ColorQ. By choosing this timelier method, these additional dilutions created some human error during the evaluation of the true concentrations for each solution and fluctuation were easily seen throughout the experiment. Average available sodium hypochlorite values were thus taken to minimize this error. 
Available lab time also contributed to a reduced power and reliability in analysed linear regression of available sodium hypochlorite. Samples were only able to be collected periodically over a 15day period. A stronger correlation could have thus been achieved by increasing the sampling period.

\section{Knowledge Translation}

During preparation of the sodium hypochlorite solutions from a newly purchased Clorox bottle, lower than expected concentrations of free available sodium hypochlorite were calculated. The expected concentration for Clorox was $5.25 \%$ rather than the concentration of $3.20 \%$ measured. Variability in the concentration of house hold bleach products can thus drastically effect the efficacy of solutions prepared. This fact could attribute to why it is recommended that a slightly lower $1: 20^{\text {th }}$ dilution be used to achieve the desired 200ppm concentration within the opaque spray bottles from $5.25 \%$ bleach. The recommended dilution thus helps to increase the efficacy of lower expected bleach product concentrations (3). With regards to a large variability of available sodium hypochlorite in bleach product, it is still important to recommend the practice of preparing fresh sodium hypochlorite solutions within spray bottles daily. For the low cost of house hold bleach product, it is not very cost effective to hold onto solutions prepared within spray bottles for multiple days (3). That said, since available sodium hypochlorite is moderately stable within spray bottles, the use of spray bottle solutions for longer than a day should continue to be considered a low hazard and not be reprimanded. From these findings, emphasis should be made towards educating safe use regarding disinfection solutions preparation while erring on the side of caution. This applies to environmental health officers or any other health care worker or official.

\section{Future Research}

Use a large-scale titration to enumerate the available sodium hypochlorite in opaque spray bottles within the 100$200 \mathrm{ppm}$ range to increase the experiment's validity. In addition, a similar experiment could be performed but with the added variable for active use of spray bottles vs non-used spray bottles to evaluate the affect active use can play on the degradation on available sodium hypochlorite. Lastly a similar experiment could be performed on the active degradation of quaternary ammonia in spray bottles to evaluate its stability within a food service establishment setting.

\section{Conclusion}

This study determined that sodium hypochlorite solutions prepared within opaque spray bottles are stable under food service establishment conditions for at least two weeks. Currently environmental health officers working under health authorities recommend that all sodium hypochlorite solutions in spray bottles must be prepared daily to ensure that available sodium hypochlorite is present within a 100-200 ppm range. Contrary to the health authority's recommendation, each opaque spray bottle tested maintained a concentration greater than $100 \mathrm{ppm}$ available sodium hypochlorite over a 15-day period. Furthermore, by evaluating each solutions degradation rates obtained from the linear regression models suggests that these solutions could remain stable for longer than 30 days. In summation, to preserve the efficacy of daily sodium hypochlorite disinfectant use, it is important 
to store these bottles in areas that are cooler in temperature and that are less exposed to ambient light.

\section{Acknowledgements}

Thanks to Helen Heacock for undertaking the supervision of this project and to Fred Shaw for the material and laboratory assistance. Lastly, recognition should be given to Jeremy Chow for suggesting this research project.

\section{Competing Interest}

The authors declare that they have no competing interests.

\section{References}

1. Flint JA, Van Duynhoven YT, Angulo FJ, DeLong SM, Braun P, Kirk M, et al. Estimating the Burden of Acute Gastroenteritis, Foodborne Disease, and

Pathogens Commonly Transmitted by Food: An International Review. Clin Infect Dis [Internet]. 2005;41(5):698704. Available from: papers://19cf457c-68ad-4d71babead8992c3079c/Paper/p283\%5Cn http://cid.oxfordjournals.org/look up/doi/10.1086/432064

2. Gaulin C, Lê M, Shum M, Fong D. REVISED AUGUST 2011 Disinfectants and sanitizers for use on food contact surfaces General Information about. 2011;(August):1-15.

3. Pfuntner A, Rehs MA. Sanitizers and disinfection: the chemicals of prevention. Food Saf Mag 4. 2001;

4. Ha JH, Choi C, Lee HJ, Ju IS, Lee JS, Ha S Do. Efficacy of chemical disinfectant compounds against human norovirus. Food Control [Internet]. 2016;59:5249. Available from: http://dx.doi.org/10.1016/j.foodc ont.2015.04.040

5. Canadian Food Inspection System Implementation Group. Food Retail and Food Services Code. 2004;(September):1-89.

6. Health Canada, BC Laws. Food Premises Regulation. British Columbia: Health Canada; 1999 [cited 2016 Oct 20]. Available from:

http://www.bclaws.ca/EPLibrarie s/bclaws_new/document/ID/frees ide/11_210_99

7. Feliciano L, Li J, Lee J, Pascall MA. Efficacies of Sodium Hypochlorite and Quaternary Ammonium Sanitizers for Reduction of Norovirus and Selected Bacteria during WareWashing Operations. PLoS One. 2012;7(12).

8. Iqbal Q, Lubeck-Schricker M, Wells E, Wolfe MK, Lantagne D. Shelf-life of chlorine solutions recommended in Ebola virus disease response. PLoS One [Internet]. 2016;11(5):1-12. Available from: http://dx.doi.org/10.1371/journal. pone. 0156136 
9. Waters BW, Hung YC. The Effect of $\mathrm{pH}$ and Chloride Concentration on the Stability and Antimicrobial Activity of Chlorine-Based Sanitizers. J Food Sci. 2014;79(4):622-8.

10. Group BC, Tower O. OxyChem Sodium Hypochlorite Handbook Soda Bleach Solutions Handbook. Analysis. 2000;

11. Clarkson RM, Moule a J, Podlich HM. The shelf-life of sodium hypochlorite irrigating solutions. Aust Dent J [Internet]. 2001;46(4):269-76. Available from:

http://eutils.ncbi.nlm.nih.gov/entr ez/eutils/elink.fcgi?dbfrom $=$ pub med\&id $=11838874 \&$ retmode $=$ re f\&cmd=prlinks\%5Cnpapers $3: / / p$ ublication/uuid/0D93DA0D0BED-40D5-87A4378A290A0733

12. Rutala $\mathrm{W}$ a, Cole EC, Thomann CA, Weber DJ. Stability and bactericidal activity of chlorine solutions. Infect Control Hosp Epidemiol [Internet]. 1998;19(5):323-7. Available from:

http://www.ncbi.nlm.nih.gov/pub med/9613692

13. Law A. Effectiveness of Bleach Sanitizers Exposed to the Environment. 2002-2004. [cited
2016 Oct 18]. Available from Archived BCIT Research Projects.

14. CLEANING AND SANITIZING - THERE IS A DIFFERENCE! Mixing Other Chemical Sanitizers : When mixing and using any commercial sanitizer product, you should always follow the. 1994;1994.

15. Health EP. How to Mix an Approved Sanitizing Solution. $1800 ; 7517$.

http://www.albertahealthservices. ca/assets/wf/eph/wf-eh-how-mixan-approved-sanitizingsolution.pdf

16. LaMotte. ColorQ Photometer for Pool and Spa. Cited 20

November 2016. http://www.testkitcentral.com/pr odImages/2012/ColorQPRO7.pdf

17. Ronald L. F. Pool \& Spa Operator Handbook. 2014 Edition. United States: National Swimming Pool Foundation; 2014.

18. Statistical Software | Sample Size Software | NCSS [Internet]. Ncss.com. 2016 [cited 20 November 2016]. Available from: https://www.ncss.com/ 